\title{
A relação entre creche e família: entraves que permanecem há décadas
}

Resumo: O texto apresenta os principais resultados de uma pesquisa realizada em 1997 que nunca foi publicada. Como a proposta do dossiê é revisitar a história das lutas pelas creches e pela educação infantil no Brasil, constatamos que a discussão aqui apresentada permanece atual e, por isso, pode contribuir para o registro histórico e assim colaborar para a compreensão dos tempos atuais. O recorte temático focaliza a relação entre as creches e as famílias atendidas, mostrando que algumas problemáticas dessa relação identificadas trinta anos atrás ainda podem ser observadas no cotidiano das creches. As discussões apoiam-se em pressupostos teóricos sócio interacionistas construtivistas para interpretações sobre o desenvolvimento humano diante das relações entre profissionais e familiares, com seus reflexos sobre as crianças pequenas, e sobre o papel das creches em um contexto social mais amplo.

Palavras-chave: Creche. Relação creche-família. Teorias sócio interacionistas construtivistas. Representações sociais.

\section{The relationship between day care and the children's families: barriers remain for decades}

Abstract: The text presents the main results of a survey conducted in 1997 that was never published. As the proposal of the dossier is revisiting the history of the struggles by the kindergartens and child education in Brazil, we note that the discussion presented here remains current and, therefore, can contribute to the historical record which contributes to the understanding of current times. The theme focuses on the relationship between the day care and the children's families, showing that some problematic relationship identified 30 years ago can still be observed. Discussions rely on theoretical constructivist socio- interacionist approaches to human development, observing the relations between professionals and families, with their reflections on young children, and about the role of day care in a wider social context.

Keywords: Daycare. Daycare-family relationship. Socio-interacionist constructivist theories. Social representations.

\footnotetext{
' Doutora em Educação pela Universidade Federal de Pernambuco. Docente do Centro de Educação da Universidade Federal de Alagoas. E-mail: telma.vitoria@cedu.ufal.br
} 


\section{Introdução}

$\mathrm{T}$

rinta anos atrás defendemos uma dissertação de mestrado que apresentou uma investigação sobre as representações das, então, educadoras ${ }^{2}$ de creche sobre as mães / famílias ${ }^{3}$ das crianças atendidas. Nela argumentamos especialmente sobre a necessidade das creches trabalharem para desenvolver as relações com as famílias e ponderamos sobre a influência da formação prévia e em serviço das profissionais para esse trabalho, considerando as concepções das mesmas sobre família, creche, criança e educação infantil. Para isso, apresentamos os conhecimentos teóricos até então desenvolvidos sobre interações e representações sociais, juntamente com análises da conjuntura sócio histórica da época.

Neste artigo apresentamos os resultados daquela pesquisa, com algumas atualizações bibliográficas, e o que na época já era conhecido teoricamente, mas que não se mostra presente nas concepções das atuais profissionais da educação infantil. Importante lembrar que até a Lei de Diretrizes e Bases da Educação Nacional de 1996 (BRASIL, 1996) as creches eram instituições que atendiam crianças de zero a seis anos; a partir daquela lei, passaram a ser designadas como aquelas que atendem crianças até três anos de idade. Os resultados da pesquisa foram produzidos pouco antes da promulgação da lei, mas parecem atuais especialmente quando se trata do atendimento coletivo de crianças até três anos. Assim, convidamos o leitor a viajar no tempo, refletindo sobre o que mudou nestes trinta anos de luta pelos direitos das crianças e suas famílias promulgados desde a última Constituição Nacional (BRASIL, 1988), no que se refere ao cotidiano das creches ${ }^{4}$.

Atualmente, após a migração das creches para os sistemas de ensino, constatamos forte influência da escolarização no cotidiano dessas instituições, bem como o fortalecimento da profissionalização das professoras que trabalham na educação infantil. Esse cenário, a nosso ver, traz avanços, mas também novas dificuldades. Embora tenhamos avançado sobre os direitos de voz e fala das crianças, aquelas que não falam ou não falam direito continuam silenciadas; e os direitos das profissionais parecem se sobrepor aos delas. Porém, esta questão não será tratada neste artigo, entendida como uma questão específica a ser focalizada nas lutas pela continuidade de existência das creches, e dos direitos das crianças de zero a três anos de idade, sempre ameaçadas nas discussões educacionais e de políticas públicas voltadas à educação infantil.

\footnotetext{
2 Embora na Lei de Diretrizes e Bases da Educação Nacional se atribua ao professor a educação infantil, manteremos a designação adotada anteriormente à lei. Também as designaremos pelo gênero feminino por serem elas o grande contingente de trabalhadoras neste segmento.

${ }^{3}$ Como os contatos se dão mais freqüentemente com as mães, citaremos apenas as mães / famílias, embora defendamos a idéia de que é importante uma maior participação dos pais.

${ }^{4}$ É muito importante registrar aqui um especial agradecimento à Professora Doutora Maria Clotilde Rossetti Ferreira que foi a orientadora daquela dissertação de mestrado e que continua apoiando até os dias atuais este e outros empreendimentos em prol da defesa e do incremento dos direitos das crianças, em especial das crianças pequenas.
} 


\section{A creche é solução ou problema?}

Até a virada do século XXI continuava a existir uma polêmica sobre as influências da creche no desenvolvimento da criança. Idade e tempo de permanência foram questionados quanto à capacidade da criança enfrentar separações contínuas da mãe e estabelecer outros vínculos afetivos. Fox \& Fein (1990), por exemplo, criticavam correlações estatísticas entre a presença da criança na creche e problemas de desajuste social na idade escolar, por não considerarem outros fatores, como o seu contexto familiar.

Estudos que se apoiavam na teoria do apego, por exemplo, utilizando o método da "situação estranha" proposto por Ainsworth (1978), aplicado na creche, apresentavam como resultado baixa frequência de comportamentos de busca da mãe, por parte da criança, sendo este interpretado como sinal de comprometimento no apego com a mãe. Fox \& Fein (op. cit.) alertavam para o fato de que a creche não é um local estranho para a criança e, por isso, não provoca ansiedade nem a necessidade de buscar a mãe. Outras variáveis não controladas nestes estudos foram apontadas, como os motivos e expectativas da mãe sobre a decisão de colocar um filho pequeno na creche. Estes podem ser diferentes se, por exemplo, aquela decisão representa o fato da mãe não ter outra alternativa ou se é uma opção. Além disso, não apresentavam considerações a respeito de como as crianças eram vistas pelas educadoras.

Outra tendência se revelava por pesquisadores que partiam de um pressuposto teórico diferente daqueles fundamentados na organização da família nuclear como a única possível de favorecer um desenvolvimento saudável (VALSINER, 1987). Apoiados em estudos transculturais e interdisciplinares junto à antropologia, história, sociologia e outros, que evidenciam diversidades de modelos de cuidado e educação infantil, investigavam as condições de atendimento à criança pequena em ambientes coletivos. Desta forma, sua contribuição se deu no sentido de estabelecer critérios de qualidade, como Zabalza (1998) e Bondioli (2004), no que se refere a instituições de educação infantil.

A pesquisa brasileira vinha acumulando estudos que demonstravam a necessidade de se desenvolver políticas de educação abrangendo a educação infantil para superar a histórica tradição filantrópico-assistencialista. Como exemplos, citamos os trabalhos de Kramer \& Souza (1988) e Rosemberg (1989a, 1989b). Também o MEC, acompanhando a tendência de outros países, subsidiou a criação do primeiro instrumento que organiza alguns critérios de avaliação do atendimento em creches e redes de creches (CAMPOS \& ROSEMBERG, 1995). Esta tendência se manteve até 2009, com a publicação pelo MEC dos Indicadores de qualidade para a Educação Infantil (BRASIL, 2009), onde se encontra como um dos indicadores, as relações com as famílias.

Apoiado em pressupostos teóricos sócio interacionistas, o Centro de Investigação sobre Desenvolvimento e Educação Infantil - CINDEDI - engajado nas questões sociais sobre o atendimento das crianças pequenas, passou a investigar alguns elementos mediadores do desenvolvimento humano, através da observação das interações adulto-criança e criança-criança em creches (ROSSETTI-FERREIRA et. al, 2004). Através de um processo dialético entre ações e reflexões, no exercício entre teoria e prática, o CINDEDI participou ativamente dos movimentos então emergentes, como a constituição do Movimento Interfóruns 
da Educação Infantil do Brasil - MIEIB - e outros, e buscou avançar em propostas teóricas para a compreensão do desenvolvimento humano. Um resumo destas concepções teóricas está exposto a seguir.

\section{Interações, Construção de Conhecimentos e Desenvolvimento}

O desenvolvimento humano se dá nas e pelas interações que o indivíduo estabelece com seu meio, não ocorre somente na infância e adolescência e nem de forma constantemente ascendente. É um processo mediado simbolicamente por um contexto histórico e social, onde as crises têm um papel fundamental para superação de formas de organização das habilidades individuais e coletivas para outras mais adequadas a novas circunstâncias, as quais exigem toda uma reorganização micro e/ou macrossocial. Nas reorganizações ocorrem ganhos e perdas de possibilidades de desenvolvimento, isto é, habilidades podem ou não ser desenvolvidas conforme as circunstâncias com as quais o indivíduo se depara no decorrer de sua história de vida.

Nas interações dos indivíduos ocorre contínua e recíproca construção de significados, através de recortes e interpretações do que é percebido. Mesmo o conhecimento prático que se constrói através das interações com objetos, tem seu componente conceitual / representacional, visto que os objetos são sempre significados pelo meio social através da atividade, constituída pela cognição / afetividade presentes (OLIVEIRA e ROSSETTI FERREIRA, 1993; OLIVEIRA, 2011).

Pressupõe ainda que a experiência humana não pode ocorrer de forma imediata, ou seja, ela é sempre mediada por vários elementos internos e externos, que se transformam em signos culturais à medida que vão sendo apropriados e transformados em instrumentos para novas interações. Desde o início da vida, os elementos mediadores vão se tornando, cada vez mais simbólicos e abstratos, menos dependentes de elementos concretos.

$\mathrm{Na}$ creche a educadora é mediadora importante do desenvolvimento infantil. Da interação com ela, a criança apreende os modelos culturais de ação sobre o meio, os quais posteriormente se tornam mediadores de sua ação. Os adultos, por sua vez, têm também sua ação mediada por uma rede de signos e símbolos culturais, os quais se encontram em contínua transformação e/ou construção. Nesta interação estão presentes elementos da criança e do adulto, internos e externos que atuam como meios (contextos e recursos ou instrumentos) de desenvolvimento. O universo de significações no qual o indivíduo está mergulhado influencia continuamente sua ação sobre o mundo, sua construção de conhecimentos e a constituição da subjetividade (VYGOTSKY, 1984; WEREBE \& NADEL, 1986).

No que diz respeito aos elementos mediadores das interações criança-criança e adulto-criança na creche, fomos capazes na época de apontar inicialmente algumas condições que as influenciam, como o número de crianças, tamanho e forma de organização do ambiente, rotinas de trabalho e disponibilidade de objetos (OLIVEIRA, 1994; CARVALHO et. al. 2012).

Juntamente com esses estudos, o CINDEDI se deparou com a teoria das representações sociais, a qual contribuiu com os avanços de suas pesquisas. Seguem alguns pressupostos dessa teoria. 


\title{
Contribuições da Teoria das Representações Sociais
}

A representação social foi definida por Moscovici como "...uma modalidade de conhecimento particular que tem por função a elaboração de comportamentos e a comunicaşão entre indivíduos" (1978, p.26). Compõe-se de idéias, imagens, concepções nas quais os indivíduos se apóiam para a atividade, e de processos, visto seu caráter dinâmico, que permite constantes reformulações dos conteúdos já constituídos.

A ação e a comunicação social se dão através de regulações entre as atividades dos indivíduos, onde se constróem significados que possam ser compartilhados por um grupo, comunidade ou sociedade. A representação social seria uma parcela da "substância simbólica longamente elaborada" socialmente que permite aos indivíduos agirem e se identificarem. Funcionam também para dar significados aos objetos e fenômenos não familiares. Quando isto acontece, os significados já existentes são influenciados pelo dado novo, exigindo novas regulações da ação social, de onde devem surgir novas configurações a serem compreendidas pelo grupo. As representações sociais se fazem, assim, através da interpretação, simbolização e da expressão dos indivíduos em interação. Compõem-se de aspectos sociais, materiais e ideacionais, e constituem espaços de elaboração nos níveis inter-individual, intra-individual, situacional e ideológico (SPINK, 1994).

\begin{abstract}
...se uma representação social é uma 'preparação para a ação’, ela não o é somente na medida em que guia o comportamento, mas sobretudo na medida em que remodela e reconstitui os elementos do meio ambiente em que o comportamento deve ter lugar. Ela consegue incutir um sentido ao comportamento, integrá-lo numa rede de relações em que está vinculado ao seu objeto, fornecendo ao mesmo tempo as noções, as teorias e os fundos de observação que tornam essas relações estáveis e eficazes. (MOSCOVICI, 1978, p.49).
\end{abstract}

As representações sociais parecem muito próximas àquilo que é chamado de "senso comum", que normalmente é tomado como um corpo de conhecimentos, teorias e/ou concepções do qual um grupo social se apropria e no qual podem ser encontrados elementos do conhecimento científico, que de alguma maneira foram "deturpados" ou fragmentados. As transformações sobre o conhecimento científico ao nível das relações sociais são vistas como adaptações necessárias à utilização destes conhecimentos na vida cotidiana. Esta teoria nos interessou na medida em que se encontra na interface de várias áreas do conhecimento, a saber, a psicologia social, a sociologia, a antropologia, a história e outras.

Segundo Moscovici (1988), as representações sociais dispensam a atenção consciente dos indivíduos para existir, apesar das transformações que podem estar ocorrendo sobre elas. Mas podemos captar mudanças, por exemplo no que nos interessa aqui, sobre a emancipação feminina e a creche. Seus principais elementos são as pessoas, que se relacionam, pensam, se desenvolvem e constroem conhecimentos.

Era comum pessoas que não têm familiaridade com creches imaginarem um monte de crianças com expressões tristonhas e narizes escorrendo em seu recinto. Esta imagem se constituiu no decorrer de quase cem anos em que elas funcionaram como "depósitos" para crianças "carentes". A idéia de "depósito" e de "crianças carentes" fazia parte de representações formadas com a contribuição das teorias psicológicas que apresentavam a mãe como principal responsável para o desenvolvimento infantil saudável. Crianças que ficavam sem a mãe seriam carentes a priori e mãe que é mãe não abandona o(s) filho(s) na 
creche(ROSEMBERG, 1982)5. Assim, as creches ficaram no lugar e função de meros depósitos, o que combinava bem com a precariedade de condições de atendimento. Além disso, uma rigidez aparecia também por dentro das creches, quando se observava a monotonia de suas atividades e tendência a atender o maior número possível de crianças em detrimento da qualidade.

As maneiras como a sociedade avalia a função da creche parecem estar associadas às representações sobre criança, mães e/ou famílias. Por exemplo, uma pessoa pode avaliar a creche como "mal necessário" apoiando-se em uma representação de criança mais voltada para um aspecto angelical, indefeso, pleno de pureza e bondade, que necessita apenas do carinho materno para se tornar uma pessoa boa e completa. Esta representação pode coexistir com outra de que a creche pode servir muito bem ao propósito de tirar as crianças da rua, que são vistas como potencialmente nocivas à sociedade, pois podem se tornar delinquentes. A creche pode ser interessante para o filho da empregada doméstica, mas não para o filho da amiga, o qual deve frequentar uma escolinha particular.

Observávamos mães que buscavam status socioeconômico, ao poder pagar uma escolinha particular, trocando a instituição pública pela outra, independente da comparação de qualidade entre elas.

Segundo esta teoria, podemos interpretar que as educadoras de creche também recebem pressões variadas sobre as suas representações de criança, maternidade, educação infantil, creche, conforme seus grupos de pertença, exercendo pressões diferentes sobre a sua conduta, valores, opiniões e crenças. Os conteúdos abordados em um projeto de formação profissional também influenciam a dinâmica de suas representações. Por exemplo, uma educadora pode ter convivido, desde a sua infância, com uma imagem de creche vinculada a ações de caridade e chegando na creche, participa de discussões sobre direitos das crianças; ou a educadora poderia já ter trabalhado em uma instituição de educação infantil religiosa e passa a trabalhar em uma instituição pública que advoga a laicidade. Em casos assim, é possível ocorrer rupturas em relação a concepções antigas, necessárias para a formação de novas representações, as quais se tornarão mediadoras da ação (SPINK, 1994).

\section{Formação Profissional para a Creche}

Em abril de 1994, realizou-se em Belo Horizonte o Encontro Técnico de Formação do Profissional de Educação Infantil, que reuniu pesquisadores, militantes e representantes do poder público, a partir do qual foi elaborado um documento que sintetizava as principais determinações e questionamentos relacionados à questão (BRASIL, 1994). Caracterizava o trabalho em creche como especializado, que subentende conhecimentos de diversas áreas, como psicologia do desenvolvimento, pedagogia, saúde infantil e outros. Antes disso, Campos et. al. (1987), demonstravam a tendência na educação brasileira a menor qualificação e status profissional quanto menor a idade dos indivíduos com quem se trabalha, até hoje no Brasil.

Além de outras contribuições importantes naquele documento, destaca-se aqui a de Kramer, que alertou para o perigo de se tratar essa formação da mesma forma como se tratou o problema da repetência escolar e como vinham sendo tratados os problemas da formação dos demais professores, através da ideia

${ }_{5}^{5}$ Primeiro texto brasileiro que criticou essa noção, então predominante. 
de compensação de carências. Apontou ainda a necessidade de se traçar diretrizes de ação, sendo que estas deveriam corrigir o erro de se realizar ações emergenciais e sem continuidade.

No mesmo documento, Campos questionou as formas de trabalho que dividem as tarefas de educação e de cuidados entre profissionais mais e menos qualificados. Argumentou contrária a estas iniciativas pela fragmentação que provoca e apontou a inadequação da formação oferecida pelo magistério.

Ou seja, ambos necessitam de um novo tipo de formação, baseada numa concepção integrada de desenvolvimento e educação infantil, que não hierarquize atividades de cuidado e educação e não as segmente em espaços, horários e responsabilidades profissionais diferentes (p. 37).

Ela propôs diferentes níveis de formação sem que se faça divisão de tarefas no trabalho, de forma que formandos e profissionais possam trabalhar lado a lado, juntamente com uma política de valorização da carreira profissional.

O documento converge para que a formação prévia mínima deva ser a de magistério, acompanhada de formação constante e/ou permanente em serviço, a qual deve contemplar conteúdos voltados a conhecimentos teóricos e ao desenvolvimento de habilidades específicas, como a observação, a narrativa e o registro. Poucos anos após a emergência daquelas propostas, passou-se a discutir na educação infantil formações baseadas em conteudos conceituais, atitudinais e procedimentais (ZABALA, 1998).

Um consenso importante, apoiado por estudos internacionais, como de Spodek (1991) e Melhuish (1991) foi a certeza de que promover a formação do profissional de educação infantil representa a estratégia mais eficaz para a melhoria da qualidade da educação das crianças. O desafio se colocava no sentido de romper com a perspectiva da função "materno-substitutiva", mas sem atropelar as formações organizadas como "pacotes pedagógicos", como no caso dos programas médico-higienistas e da educação compensatória (HADDAD, 2016).

\section{Resultados de uma pesquisa que discutiu a relação da creche com as famílias baseada nas representações de educadoras e nas concepções sócio interacionistas construtivistas do desenvolvimento humano}

Apoiadas nas conceituações teóricas apresentadas anteriormente e com alguma inspiração sobre Análise de Discurso, analisamos os conteúdos de entrevistas realizadas com educadoras de duas creches diferentes quanto a população atendida e formação em serviço, recortando as representações que as educadoras tinham a respeito das mães e seu trabalho com elas (VITORIA, 1997) ${ }^{6}$. A creche 1 tinha um histórico de investimento sistemático na formação prévia e em serviço, e atendia uma população de nível socioeconômico melhor do que a creche 2 que, contrariamente, não apresentava o mesmo investimento em formação e as famílias atendidas eram todas de nível socioeconômico baixo. Apresentamos a seguir os principais resultados das análises realizadas a partir das entrevistas.

\footnotetext{
${ }^{6}$ Foram realizadas entrevistas com 17 educadoras, baseadas em um roteiro semiestruturado, que abrangia todos os momentos da rotina de seu trabalho. Cada entrevista resultou em torno de 4 horas de gravação em áudio. As entrevistas foram transcritas e, em seguida, foram feitos recortes de todos os momentos em que surgiam referências à mãe, ao pai ou à família da criança. A partir desses recortes procedeu-se uma análise sobre os conteúdos potencialmente promovedores das relações com as famílias, e os contrários.
} 
As educadoras de ambas as creches apresentaram comentários sobre a importância de trocar informações com as famílias a respeito do cotidiano das crianças, o que envolve a necessidade da educadora dedicar tempo e atenção aos contatos com as mães. A creche 1 apresentou maior expectativa sobre a continuidade do cuidado e educação em casa, enquanto que a creche 2 , mais justificativas que levam as mães a não conseguirem esta continuidade. No entanto, apresentaram, também, ressentimentos sobre a falta de envolvimento observada nas famílias, seja em relação aos filhos, seja sobre o trabalho da creche com eles.

Nas falas das educadoras da creche 1 notamos a ideia de uma espécie de desequilíbrio de conhecimentos entre educadoras e mães, tendo as primeiras maior oportunidade de construí-los e organizá-los, o que parecia levá-las a adotar certa posição de superioridade em relação às mães. Na creche 2, as educadoras se colocavam em pé de igualdade com as mães em relação aos conhecimentos sobre educação e desenvolvimento infantil. O desequilíbrio neste caso, parecia se relacionar às condições de moradia das famílias, em geral menos favoráveis, em comparação ao que a creche oferecia às crianças.

Em ambas as creches encontramos atribuições causais sobre a família para explicar os problemas enfrentados com as crianças, críticas à conduta e à falta de interesse por parte da mesma, e uso da expressão "vem de casa" quando usada sem maiores explicações. Apesar dos conteúdos sociais e institucionais que incidiam de maneira generalizada nas falas das educadoras, cada uma delas apresentava uma maneira particular de contextualizar e de usar estes conteúdos, conforme seus recursos, necessidades e aspirações no momento da entrevista. Exemplos:

Elvira ${ }^{7}$, da creche 1, foi a educadora que apresentou menos referências que demonstrassem expectativas ou pré-julgamentos sobre as condutas adotadas pelas mães. Seus depoimentos revelaram a valorização do bom relacionamento com cada mãe e uma preocupação, um trabalho de sua parte, no levantamento de informações, na investigação e reflexão sobre a criança e seu contexto familiar. O exercício de observação parece ter assegurado também as suas afirmações a respeito da influência recíproca entre a casa e a creche no trato com a criança e a capacidade da mesma na diferenciação entre estes ambientes.

Sua colega Mirtes, ao contrário, apresentou grande ênfase nas críticas e queixas voltadas às condutas das mães, ao mesmo tempo em que uma acentuada redundância nas suas afirmações, supondo um sentimento de falta de segurança no trabalho com a criança e com a família. Ficam evidentes suas expectativas sobre a concordância das mães. Ela confundia-se ainda sobre as capacidades de discriminação da criança, em relação aos ambientes de casa e da creche. O ambiente familiar era visto por ela sempre como melhor do que o da creche.

Da creche 2, Eloisa, apesar de ter melhor formação prévia, revelou uma linguagem pobre e poucas reflexões e/ou opiniões sobre as famílias atendidas. Ela não citou problemas relacionados aos contatos diários com as mães, chegando a afirmar que estes não existiam. Revelou certo receio de receber queixas, o que apoiava nossa interpretação de que, para ela, mais importante era evitar conflitos, divergências, não levantar maus humores. Por ser uma pessoa jovem ainda, pode ser natural que apresentasse algumas dificuldades para firmar uma identidade profissional e pessoal, como a evitação que a protegia de assumir posições e opiniões.

\footnotetext{
${ }^{7}$ Nomes fictícios.
} 
Sua colega Neiva parecia não enfrentar os mesmos problemas, pois falava bastante das mães, revelando segurança no contato com as mesmas. Entretanto, apresentava comentários que revelavam a legitimação da creche por seu caráter assistencial. Ela se apoiava na valorização da creche como instituição educativa da mesma forma como na sua função de atendimento à pobreza. Poucos subsídios acompanhavam as suas representações sobre a mãe / família, levando a várias generalizações sobre problemas de comportamento das crianças, como causados pela família. Segundo ela, os problemas apareciam em famílias com poucos recursos, como a violência, alcoolismo etc.

\section{As Representações Sociais das Educadoras}

Apesar das diferenças encontradas entre as creches e educadoras, os resultados chamaram mais atenção pelas semelhanças de representações ligadas às ideias de que deve ser a mãe o elemento mais importante do desenvolvimento da criança pequena, as quais surgiram acompanhadas de um julgamento de que as mães e/ou famílias devem trabalhar pela educação dos filhos em casa e de que, geralmente, elas não cumprem a tarefa. Os depoimentos sugeriam a impossibilidade de qualquer forma de compartilhamento de cuidados e educação com as famílias, visto a ênfase apresentada nas obrigações da mãe em relação aos filhos. As educadoras pareciam buscar exercer o controle sobre o que deveria ocorrer no ambiente doméstico, desculpando apenas aquelas mães / famílias que demonstravam acentuada falta de condições socioeconômicas ou psicológicas para tal.

Os resultados mostraram que as educadoras compartilhavam com a sociedade esta representação social sobre o papel da mãe / família como principal provedora do cuidado e educação infantil, embora notamos que precisavam modificar em parte esta representação através do reconhecimento do valor da mulher que trabalha fora de casa e através da representação de creche como ambiente educacional promotor do desenvolvimento infantil.

Note-se que estas representações atribuídas às mães / famílias, por estarem presentes no universo das educadoras de ambas as creches, ocorriam à revelia das diferenças de nível socioeconômico e cultural das famílias atendidas e da formação das próprias educadoras. Apesar do processo de emancipação feminina vir pressionando a ocorrência de mudanças no papel do homem e da mulher no sistema de produção e, consequentemente, em toda a forma de organização social, incluindo aí a família e a transformação da creche em parte do sistema de reprodução da força de trabalho, constatamos que as representações sobre maternidade e/ou função materna / família pareciam se mostrar persistentes no tempo.

As representações geradas por grupos sociais dominantes, como as que se relacionam com a valorização da maternidade e da família, seriam difundidas e objetivadas para uma grande parcela da sociedade e aí persistiriam. Enquanto que para outros grupos as mesmas representações se relativizariam com maior rapidez, de forma a contemplar práticas diversas e um maior exercício da individualidade. Vejamos como surgiu esta constatação no caso das creches pesquisadas.

Na creche 1, foi enfatizada a crítica ao modelo materno-substitutivo de atendimento e apoiaramse nas capacidades de interação de crianças pequenas. Esta característica pode ter gerado mudanças em 
algumas representações das educadoras sobre a creche, não só em função da formação em serviço, mas também através da observação e constatação das oportunidades criadas para a promoção do desenvolvimento infantil. Além disso, notou-se um esforço constante para que o atendimento se desse da forma mais individualizada possível, ainda que respeitando as regras e rotinas institucionais. Na creche 2, depoimentos de valorização da creche pelas oportunidades de desenvolvimento infantil surgiram ligados à ideia de "solução para a pobreza", o que tem relação com a origem assistencialista e o nível socioeconômico precário das famílias atendidas. Este conjunto de características pareceu-nos acobertar as pressões e conflitos em relação à função materna, pois é sempre priorizada a assistência às situações emergenciais daqueles que não têm o que comer ou com quem ficar, frente as quais se diluem outras e diversas necessidades individuais que surgem quando a sobrevivência está garantida.

Concordamos com Fleury (1994), que ao discutir as representações de professoras de pré-escola a respeito da criança, apontou o caráter fragmentado e contraditório dessas representações, a não linearidade entre elas e a ação educativa, apesar de suas influências recíprocas e a "forma mais alienada, acrítica e mecânica quanto mais for estereotipado este "corpus" de ideias preestabelecidas" (idem, p. 133). Uma representação idealizada de mãe, apaga as diferenças sociais encontradas na concretude das pessoas reais com quem elas mantém contato diário.

A representação social das educadoras entrevistadas sobre as mães / familias da creche parecia se colocar como uma das dificuldades para que assumissem a função de mediadoras da relação creche - família como parte do seu trabalho. Pois para assumir esta função, seria necessário reconhecer e mudar as expectativas, de forma a encarar com mais naturalidade todas as formas de condutas das mães e/ou famílias em relação aos filhos ou à creche, desde as menos atentas às mais exigentes, desde as mais rígidas às menos convencionais. Seria preciso trabalhar, por exemplo, as representações sobre família pobre, que apresentam vários preconceitos girando em torno da precariedade de condições materiais e suas consequências no futuro da criança.

Uma das conclusões a que chegamos foi que deparar-se frente ao cotidiano de uma creche e, principalmente, participar deste como ator social, seja no papel de mãe, seja no de educadora, implica enfrentar a contradição que se instaura nas representações relacionadas à maternidade, questionando-as. Elementos históricos e antropológicos estão presentes nestas representações, como Ariès (1968) e Badinter (1985) auxiliaram a elucidar, mostrando diferentes formas do trato com crianças pequenas na história.

As representações sociais da maternidade pareceram ocorrer mais através da experiência cotidiana de contatos entre educadoras e mães (conhecimentos de senso comum, construídos através de uma história de interações), do que através de conhecimentos sistematizados e difundidos em programas de treinamento e formação em serviço. Do contrário, haveria mais sinais de questionamentos ou argumentos mais elaborados, entre as educadoras da creche 1 , em relação aos próprios julgamentos sobre as mães.

\section{Breve reflexão sobre as relações entre creche e famílias}

Até poucos anos atrás, era mais comumente encontrada a prática de receber e entregar as crianças no portão da instituição. Raramente as mães adentravam o recinto onde seu(s) filho(s) permaneciam, a não ser em ocasiões excepcionais, como em festas e, em algumas creches, no período de 
adaptação da criança. Geralmente a instituição organizava sua rotina de forma que uma pessoa ficava no portão recebendo e/ou entregando as crianças, o que resultava em um contato mínimo entre as mães e a pessoa com quem seus filhos permaneciam a maior parte do tempo. Esta prática começou a ser questionada a partir da década de 80, através de uma série de argumentações: o caráter autoritário da prática pela falta de transparência; sofrimento e queda de produtividade no trabalho das mães que desconheciam as condições de atendimento de seus filhos; grande freqüência de queixas recíprocas existentes entre mães e educadoras; impossibilidade de se tratar os conflitos decorrentes e manifestações no comportamento das crianças como reflexo das relações mal trabalhadas (ROSEMBERG, 1982; HADDAD, 1987). Fomentou-se assim, a discussão sobre a relação creche - família e sobre estratégias para abrir a creche à maior participação das famílias.

Hoje é possível encontrar creches abertas, mais ou menos abertas, fechadas... O processo está ocorrendo, não sem dificuldades. Por um lado, a presença das mães dentro da creche normalmente é encarada pelas educadoras como perturbadora e, por outro, é comum as mães não saberem como agir e como interpretar adequadamente o que lá presenciam.

As educadoras parecem construir uma posição de si superior à das mães. Usando o discurso assistencialista, elas depreciam as condições de vida das famílias; ou pelo discurso escolar, colocam-se como aquelas que ensinam o que é certo e depreciam as competências das famílias. Contudo, as considerações acima não devem ser tomadas de forma absoluta, mas sim, como uma das posições, dentre outras possíveis, que às vezes elas adotam em relação às mães / famílias, visto que se mostram capazes também de se colocar frequentemente como mediadoras da relação creche - família.

Expressões de ressentimento e queixas por parte das educadoras em relação à falta de atenção das mães já constituíam assunto presente na literatura sobre creches, como em Carvalho e Vianna (1994), onde se encontram elementos para uma discussão mais ampla sobre a rivalidade observada entre educadoras e mães, e onde estão em jogo a defesa de limites entre os espaços público e privado em transformação, além da disputa pelas atribuições de cada um dos papéis sociais e sua respectiva valorização.

É possível que, em parte, as queixas das educadoras da pesquisa estivessem fundamentadas num dado de realidade ainda atual, que atinge a todas as classes sociais. Isto é, a diminuição das oportunidades de contatos e trocas afetivas entre pais e filhos, observada no modo de vida e organização social ligados à urbanização crescente, crise econômica, emancipação feminina etc.

Por outro lado, observávamos que as mães / famílias, pareciam se sentir culpadas nesta condição e costumavam exagerar na oferta de presentes aos filhos como forma de expressão afetiva. Em nossa perspectiva, aquele contexto social acirrava o individualismo, a ambição profissional, a conquista de condições materiais mais confortáveis e sofisticadas, enquanto que a creche podia se apresentar na contramão desse processo, pelo seu potencial de promover o sentido de coletividade nos relacionamentos, afetos e da coisa pública, o que parece continuar presente.

Outra conclusão a que chegamos foi que as concepções que se formam sobre a mãe / família usuária e sobre a creche influenciam no modo de relacionamento entre elas (KUHLMANN Jr., 1991). Do 
ponto de vista da mãe, a creche assistencialista lhe presta um enorme favor. Esta "caridade" a coloca no papel de alguém que deve um sentimento de gratidão e obrigações, pois os sinais de insatisfação ou queixa, atrasos na chegada ou saída, faltas em reuniões ou levar a criança sem estar trabalhando, seriam vistas como ameaça de algum consequente prejuízo à criança. A creche considerada como direito da criança e opção da família deve mantê-la informada sobre o atendimento ao(s) seu(s) filho(s) e esta, por sua vez, pode exigir coisas sobre o trabalho desenvolvido. A maior transparência nas mútuas informações exige da família outro tipo de responsabilidade, pois passa a ser necessário conhecer as possibilidades e limitações da própria creche em relação às suas demandas. Por outro lado, a abertura da creche para considerar as dificuldades e necessidades individuais leva as famílias a se comprometerem mais com a educação de seus filhos, promovendo maior envolvimento das mesmas.

Ainda é forte, em nossa sociedade, a valorização da existência da família nuclear tradicional, apoiada na divisão de responsabilidades entre o homem e a mulher, cabendo a esta o cuidado e educação da criança pequena. Por isso, a creche representa, ao mesmo tempo, motivo de culpa e de alívio. Culpa por causa da tendência das pessoas a acreditarem que sempre a criança estaria melhor com a mãe e esta, por sua vez, não está cumprindo sua obrigação. Alívio porque a creche resulta em uma enorme ajuda para ela, dentre outras necessidades, cumprir a sua segunda jornada de trabalho.

Assim, vimos a mãe se sentindo retaliada e culpada no seu papel e por isso reagindo com queixas frequentes e ataques verbais à creche ou às pessoas da creche. A educadora, perturbada pela presença da mãe e para se defender, criticando também suas ações para com o filho. Ainda é comum no cotidiano das creches ocorrências de críticas recíprocas que sugerem uma relação de competição e/ou rivalidade constante entre elas, às vezes mais velada, às vezes mais explícita.

Parece que quando a mãe e/ou família não está satisfeita ou tem alguma situação mal resolvida com a creche, normalmente muda a sua atitude. Ela se torna insegura e pouco colaboradora, por vezes atuando de forma a prejudicar o bom andamento do trabalho, por exemplo, passando a chegar atrasada, dizendo coisas diferentes para diferentes pessoas da creche ou mesmo deixando de levar o(a) filho(a). A educadora da creche, por sua vez, também reage diferentemente com as mães e/ou famílias próximas e com aquelas mais distantes ou difíceis de manter contato. Assim como a criança pode apresentar reações frente às crises do relacionamento entre os pais, observa-se que ela também pode se manifestar frente às crises da mãe / familia em relação à creche ou à pessoa diretamente responsável por ela. Observa-se que quando os conflitos entre mãe e educadora são frequentes ou intensos, a criança reage, podendo variar os modos desta reação, por exemplo, para de comer, torna-se agressiva, chora para ficar na creche, isola-se, nega-se a dormir etc. ${ }^{8}$ Assim, nem sempre os problemas das crianças observados pelas educadoras "vem de casa".

As manifestações observadas na relação creche - família e seus efeitos nas crianças denotam a intensidade da afetividade ali presente, talvez a mesma afetividade que, anterior à creche, era de domínio particular e que se vê exposta ao domínio público. Torna-se "órfã" e as "roupas sujas" passam a não ser

\footnotetext{
${ }^{8}$ Estas reações das crianças devem ser tomadas como os recursos que elas têm, principalmente enquanto não dominam a linguagem verbal, para expressar aos adultos o seu desagrado, insatisfação ou sofrimento frente a qualquer situação, não somente aquela apontada acima. Para pesquisas posteriores a esse respeito, recomenda-se a leitura de Cruz (2009).
} 
lavadas somente em casa (MELLO \& CODO, 1995). Cada vez se tornou mais evidente a importância de um projeto específico para trabalhar a relação creche - família, o qual deve prever ações adequadas às situações críticas que costumam se repetir. A começar, por exemplo, pelo acolhimento à entrada de crianças e famílias novas e também a atuações específicas para trabalhar questões de alimentação, agressividade, medos, mudança de turma, controle de esfíncteres e tantos outros temas geradores de maior ansiedade nos pais e nas educadoras de creche.

Apesar das diferenças de envolvimento afetivo com a criança que observamos entre educadoras e mães, identificamos situações difíceis de avaliar se eram mais sofridas quando vividas pela mãe, em casa, ou quando vividas pela educadora na creche. Estas diferenças envolviam aspectos relacionados aos seus recursos individuais, além do fato de casa e creche serem contextos muito diferentes. Aventamos a hipótese de que, geralmente, a mãe em casa expõe menos suas dificuldades e práticas ligadas ao cuidado e educação dos filhos, enquanto que na creche, a educadora se encontra exposta aos olhares de colegas em vários momentos. Por outro lado, a mãe parece ter menos oportunidades de compartilhar ideias sobre suas práticas com outras pessoas, fazendo com que suas decisões tendam a ser mais solitárias, enquanto que as educadoras, por suas oportunidades de compartilhar entre si as experiências vividas junto às crianças, parecem construir decisões e (representa) ações mais comuns entre elas, institucionalizando-as.

Partindo do princípio de que educadoras e mães e/ou famílias podem exercer papéis complementares, a creche deverá procurar atingir uma qualidade de relacionamento entre elas caracterizada pela cooperação, comunicação frequente, com abertura e disponibilidade para discutir os conflitos, e pelo respeito mútuo. Seria de se esperar, por exemplo, que se uma educadora acredita na creche como um direito da criança, ela não deveria se importar caso a mãe trouxesse a criança para a creche mesmo quando tivesse condições de ficar com ela, fosse num dia de folga, nas férias... Se a educadora pensa que a creche se presta apenas para quando a mãe está trabalhando fora de casa, provavelmente, ela não veria com bons olhos e não trataria da mesma forma aquela mãe que lhe deixasse o filho, podendo, aparentemente, ficar com ele. E o mesmo poderia ser concluído em relação aos horários de entrada e saída das crianças na creche, que continuam oferecendo pouca flexibilidade às mães / famílias.

Assim, defendemos que a mãe / família e a educadora da creche são os principais adultos mediadores do desenvolvimento da criança que frequenta a creche, sendo necessário o estabelecimento de uma boa relação entre elas, a qual é especialmente mediada pelas representações que cada uma delas constrói sobre criança, creche e educação infantil.

\section{A Relação Creche - Família e a Formação em Serviço}

Defendemos, então, a necessidade de se trabalhar, junto às educadoras de creche, através de programas de formação continuada, assuntos mais diretamente relacionados às representações sobre maternidade, função materna e mesmo transformações do papel da mulher na sociedade, e qual função social a creche pode assumir nesse cenário. 
Na pesquisa de Vitoria (1997), notamos que a formação em serviço não garante totalmente o avanço das concepções das educadoras. Nas duas creches vimos que as educadoras que mostraram mais argumentos e segurança sobre o trabalho tenderam a se referir menos depreciativamente sobre as mães / famílias. Por outro lado, as que revelaram mais insegurança e dificuldade em responder às questões foram as que mais se queixaram ou criticaram as mesmas, parecendo necessitar da aprovação de outros para se sentirem seguras. No entanto, elas parecem não perceber que podem ter um papel mediador fundamental na preservação de um espaço para o afeto entre pais e filhos, através do seu trabalho na creche. Este papel lhes permitiria mais assertividade nos processos que apoiam o desenvolvimento biopsicossocial das crianças.

A formação continuada da creche 1 pareceu ter um efeito mais "tópico", no sentido de modificar, enriquecer ou complexificar a visão de questões, por exemplo, voltadas à integração e adaptação de crianças e famílias novas ou as que envolvem a participação de pais e educadores homens no cotidiano das creches. Para terem desenvolvido as argumentações que apresentaram nas questões sobre adaptação, estas educadoras precisaram refletir e questionar particularmente as representações sobre creche como "mal necessário" e, no exemplo da participação masculina, as representações de creche e/ou educação infantil como "universo feminino". Para implementar este trabalho, não seria necessário aprofundar o questionamento sobre as representações relacionadas diretamente à maternidade ou à função maternal que não se generalizaram.

Os assuntos relacionados à maternidade parecem envolver um comprometimento pessoal maior das educadoras. A maioria delas deve ter sido educada desde a infância para ser mãe, sendo que a sua posição em relação à maternidade deve representar um aspecto importante da sua identidade. Embora as educadoras sejam capazes de compreender muitas dificuldades por que passam as mães, é difícil para elas abdicarem da posição de quem avalia e julga o desempenho das mães, talvez porque esta seja uma forma de manter o seu próprio ideal sobre como deve se dar a maternagem. Entretanto, sabe-se que uma das piores maneiras de se tentar promover o espaço das relações afetivas é aquela que começa pelo julgamento, crítica e pela pressão de expectativas, por tenderem a gerar apenas mais tensão, culpa e resistência. Assim devem reagir as famílias, caso lhes chegue, de alguma maneira, a pressão psicológica já existente no meio social mais amplo, voltada à depreciação da creche como espaço legítimo.

Por isso, é necessário superar a prática de realizar programas intensivos, de curta duração, onde a relação entre formadores e formandos não tem continuidade. Além disso, os conteúdos nem sempre se apresentam no momento em que estão sendo mais necessários, sendo selecionados mais pela oportunidade. Esta característica parece acompanhar uma tendência comum nas creches, de agir mais em função de situações emergenciais do que organizar a ação através de planejamentos (KRAMER, 1988).

Professoras que assumem a função de coordenadoras pedagógicas, responsáveis pela formação em serviço, geralmente são jovens profissionais que se veem muitas vezes aprisionadas, por um lado, no desejo de transformar as ações de outrem e, por outro, na frustração frente às resistências encontradas. Se a pretensão de um programa de formação for o "amoldamento" da ação educativa, fica restrito o espaço da criatividade e da expressão da subjetividade. A conquista deste espaço passa pelo aprofundamento de questões éticas, mais do que pela construção de técnicas. 
Por último, há que se problematizar as relações possíveis entre formação prévia, em serviço e formação permanente ou continuada. Vimos na pesquisa de Vitoria (1997) que o nível de formação prévia pode fazer diferença no nível geral de articulação da linguagem verbal, porém ela não é suficiente, visto encontrarmos educadoras com menor repertório verbal na creche 1 (de maior nível de formação prévia), da mesma forma que encontramos educadoras da creche 2 com o mesmo nível de formação prévia de educadoras da creche 1, apresentando também um menor repertório verbal. Conforme o assunto sobre o qual as educadoras tiveram mais oportunidade de refletir e conversar nas suas respectivas creches, encontramos diferenças de repertório que influenciam na própria estrutura do discurso. Este, por sua vez, ocupa importante lugar na construção da identidade, juntamente com a prática cotidiana.

Notamos a falta de conhecimentos subsidiários para uma ação segura junto a mães / famílias, que fragmenta os contextos de vida da criança, como o caso do ambiente doméstico, não percebendo as relações que a criança é capaz de fazer entre ele e o ambiente da creche.

Encontramos vários recortes em que a educadora atribuía à família os problemas enfrentados com as crianças; em outras ocasiões, encontramos a indefinição a respeito da capacidade da criança diferenciar ou não os ambientes de casa e da creche e, em outras ainda, afirmações de que a frequência da criança na creche ajudou-a a superar dificuldades. Assim, existe certo desconhecimento sobre características das crianças, suas capacidades de interação e de construção de conhecimentos. Com maior conhecimento neste assunto, muitos dos "problemas de comportamento" que "vem de casa" poderiam ser encarados como conflitos normais de crescimento e desenvolvimento (GALVÃO, 2004).

Seria também ingênuo estabelecermos uma relação direta entre nível de formação, estrutura de linguagem e adequação de condutas no trato com as crianças e suas respectivas mães / famílias. Em nossas incursões através do cotidiano de muitas creches, constatamos a existência de um pessoal pouco qualificado e com pouco repertório verbal que revelam adequação e sensibilidade no trabalho que realizam.

Consideramos o desenvolvimento da atividade e da identidade profissional das educadoras de creche através de um movimento dialético e de múltiplas influências, onde a afetividade e a racionalidade formam uma unidade. Desta forma, a subjetividade e o conhecimento se constituem reciprocamente (DANTAS, 1992) e encontram-se em constante transformação. No processo de construção (social / individual) da identidade das educadoras de creche, estariam envolvidos:

- a conjuntura econômica, social e política na qual as creches estão inseridas;

- a cultura e política local, onde a creche pode exercer funções diferentes conforme a população atendida;

- aspectos específicos de cada instituição, com suas diversidades históricas, de condições ambientais e de qualificação profissional;

- aspectos inerentes aos tipos de atividades que ela exerce e como exerce, relacionadas ao cuidado e educação das crianças pequenas nos ambientes coletivos, como rotina, organização de objetos, programações etc;

- características biopsicossociais do bebê e/ou da criança pequena, por exigir cuidados individuais e contatos afetivos na maior parte do tempo, sendo o adulto principal mediador do seu desenvolvimento; 
- aspectos da vida pessoal, visto que também encontramos grandes diferenças entre as educadoras de uma mesma creche, independente dos investimentos em qualificação profissional ${ }^{9}$.

À medida que modificamos as práticas institucionalizadas na creche, como a forma de recepção diária das crianças e famílias, de organizar brinquedos, salas e rotinas, as modificações contribuirão para mudanças nas representações de educadores. Significa que a formação continuada deve ser acompanhada de outras medidas administrativas, de investimento nas condições concretas de trabalho dos profissionais, a fim de ampliar a sua eficácia.

\section{Para debate sobre a função social da creche}

A partir da elucidação do papel mediador das interações adulto-criança e criança-criança para o desenvolvimento nos primeiros anos de vida, pudemos enfrentar a necessidade de se redimensionar o papel das interações mãe - criança para o desenvolvimento. Este papel é tradicionalmente endossado pelas teorias do desenvolvimento que se apoiam no modelo nuclear de organização familiar, em função do qual se construiu um conjunto de argumentações contrárias ao atendimento infantil em creches, apontando este como potencialmente prejudicial ao desenvolvimento sadio da criança por ser coletivo e provocar separações frequentes entre mãe e criança.

Para o redimensionamento do papel da mãe, não parece necessário refutar as teorias existentes, mas sim contextualizá-las a partir de referenciais sócio históricos, diminuindo-lhes as pretensões de universalidade geográfica e histórica. Pesquisas que retomam a observação das interações mãe - bebê através da perspectiva sócio interacionista têm nos alertado, por exemplo, para a importância do contexto onde elas ocorrem e para as múltiplas possibilidades de determinação / indeterminação dos significados que a partir delas são construídos. É o caso dos trabalhos de Lyra \& Rossetti Ferreira (1989) sobre os processos dialógicos, de Rubino (1989) sobre o desenvolvimento da linguagem e muitos outros.

A creche com suas características concretas e simbólicas, bem como o seu contexto sociocultural, representa uma rede de possíveis e múltiplas significações, as quais se movimentam e se resignificam a cada momento. O sujeito que vive e faz esta instituição é capturado por uma rede de significações, embora tenha algum poder de transformação sobre as mesmas. Para o entendimento das relações entre a criança, a mãe / família e a educadora, buscamos olhá-las através da rede de significações que as captura e por elas é modificada (Rossetti Ferreira et. al., 2004).

A falta de parâmetros culturais que respondam às transformações sociais e auxiliem no exercício de formas de conduta adequadas a este novo universo, que é a creche como direito de cidadania, também contribui para alimentar a relação desigual e os conflitos que se observam entre creche e familia, os quais podem ainda ser vistos como parte da contradição que se mostra nas relações sociais, entre reprodução do capital e reprodução da força de trabalho, manifestando-se no microuniverso da creche, na protagonização de mães e educadoras. Nesta perspectiva, ambas estariam pressionadas por forças opostas; por um lado, a inserção da mulher no mercado de trabalho produtivo e, por outro, sua ligação ao universo das representações idealizadas de maternidade e função

9 Posteriormente à realização da pesquisa, pudemos assimilar melhor as contribuições de Bronfembrenner (1996). 
materna, construída desde a infância. Neste cenário e processo de mudanças nas fronteiras entre o que é de domínio público e privado, está ocorrendo a institucionalização de práticas de cuidado e educação coletiva de crianças, a profissionalização das educadoras e as representações das mães / famílias usuárias da creche.

Berger \& Luckmann (1994) teorizam sobre a distribuição desigual das informações e conhecimentos construídos socialmente, a qual fica evidenciada no cotidiano da creche e das instituições em geral. Neste contexto, os autores propõem a análise das "múltiplas realidades" conforme aquela distribuição e contribuem com os processos de institucionalização. Outros ainda, como Rommetveit (1986), resgatando as ideias de Wittgenstein, propõem a análise da linguagem como a possibilidade de encontros de diferentes "mundos privados", sendo ela uma "forma de vida". Ideias estas também próximas das de Habermas (apud ANDERSON, 1989), o qual coloca a linguagem como necessidade anterior à produção material, sendo assim, determinante primeira das ideias, valores e crenças sociais.

É necessário buscar contribuições de estudos realizados nas áreas da educação, da sociologia, da antropologia, da história e das ciências políticas e econômicas, além das áreas da saúde, pedagogia, administração e arquitetura. Assim, insistimos, esta construção deve receber conotação claramente multi e interdisciplinar, para tentar responder, por exemplo, se a creche representaria hoje mais um instrumento de dominação, assimilador e assimilado pelo capitalismo liberal, ou se pode representar um instrumento social de resistências às opressões sofridas pela maior parte da população.

\section{Referências}

AINSWORTH, M.D.S., BLEHAR, M.C., WATERS, E. \& WALL, S. Patterns of attachment: a psychological study of the strange situation. Hillsdale, NJ: Erlbaum, 1978.

ANDERSON, P. A crise da crise do marxismo- Introdução a um debate contemporâneo. São Paulo: Brasiliense, 1989, 3a. edição.

ARIES, P. História Social da Criança e da Família. Rio de Janeiro: Zahar, 1968.

BADINTER, Elizabeth. Um amor conquistado: o mito do amor materno. Rio de Janeiro: Nova Fronteira, 1985, 4a. edição.

BERGER, P.I. \& LUCKMANN, T. A construção social da realidade. Rio de Janeiro: Vozes, 1994, 11a. edição

BONDIOLI, Anna $\mathbf{O}$ projeto pedagógico da creche e a sua avaliação: a qualidade negociada. Campinas: Autores associados, 2004.

BRASIL. Constituição Nacional. Brasília: Congresso Nacional, 1988. 
Por uma política de formação do profissional de educação infantil. Brasília: MEC/SEF/COEDI, 1994.

Lei de Diretrizes e Bases da Educação Nacional. Brasília: Congresso Nacional, 1996.

Indicadores de qualidade para a educação infantil. Brasília: MEC / SEF / COEDI, 2009.

BRONFENBRENNER, UrieA ecologia do desenvolvimento humano: experimentos naturais e planejados. Porto Alegre: Artes Médicas, 1996.

CAMPOS, M.M.; GROSBAUM, M.W.; PAHIM, R. \& ROSEMBERG, F. Profissionais de Creche. Cadernos CEDES, No. 9, Cortez, 1987, p. 39-66.

CAMPOS, M.M. \& ROSEMBERG, F. Critérios para um atendimento em creches que respeite os direitos fundamentais das crianças. Brasília: MEC/SEF/COEDI, 1995.

CARVALHO, M. P. \& VIANNA, C.P. Educadoras e Mães de alunos: um (des)encontro. In: BRUSCHINI, C \& SORJ, B. (orgs.) Novos olhares: mulheres e relações de gênero no Brasil. São Paulo: Marco Zero, 1994, p. 133158.

CARVALHO, Ana Maria A.; PEDROSA, Maria Isabel; ROSSETTI-FERREIRA, Maria Clotilde. Aprendendo com a criança de zero a seis anos. São Paulo: Cortez, 2012.

CRUZ, Silvia Helena V. A criança fala: a escuta de crianças em pesquisas. São Paulo: Cortez, 2009.

DANTAS, H. (1992) A Afetividade e a Construção do Sujeito na Psicogenética de Wallon. In: DE LA TAILlE, Yves.; OLIVEIRA, Marta K. \& DANTAS, Heloisa. Piaget, Vygotsky, Wallon- teorias psicogenéticas em discussão. São Paulo: Summus, 1992.

FLEURY, M.G. (1994) Há uma criança dentro da professora? In: OLIVEIRA, Z.M.R. (org.) Educação Infantil: muitos olhares. São Paulo: Cortez, 1994, p. 131-158.

FOX, N. \& FEIN, G.G. (eds.) Infant day care: the current debate. Norwood, New Jersey: AblexPublishing Corporation, 1990.

GALVÃO, Izabel Cenas do cotidiano escolar - conflito sim, violência não. Petrópolis: Vozes, 2004. 
HADDAD, Lenira. A Relação Creche-Família: Relato de uma Experiência. Cadernos de Pesquisa, No. 70, São Paulo. 1987, p. 70-78.

HADDAD, Lenira A creche em busca de identidade. São Paulo: Loyola, 2016, 2a. ed.

KUHLMANN JR., Moyses. Instituições pré-escolares assistencialistas no Brasil (1899 - 1922), Cadernos de Pesquisa, No. 78, São Paulo. 1991, p. 17 - 26.

MELHUISH, E.C. Cross-national Comparison and the Interpretation of Day Care Effects. In: MELHUISH, E.C. \& WOLKE, D. (eds.) Journal of reproductive and infant psychology- special issue on international perspectives on day care for young children, No. 9 (2/3), 1991, p. 63-65.

MELLO, Ana Maria \& CODO, Wanderley. Repensando as relações creche-família. In: CODO, Wanderley (Org.) Sofrimento psíquico nas organizações. Petrópolis: Vozes, 1995.

MOSCOVICI, Serge. A representação social da psicanálise. Rio de Janeiro: Zahar, 1978.

MOSCOVICI, Serge Notes towards a description of social representations, European Journal of Social Psychology, Vol.18, 1988, pp. 211-250.

OLIVEIRA, Zilma M.R. \& ROSSETTI FERREIRA, Maria Clotilde. O valor da interação criança-criança em creches no desenvolvimento infantil. Cadernos de Pesquisa, No. 87, São Paulo. 1993, p. 62-70.

OLIVEIRA, Zilma M.R. (org.) Educação infantil: muitos olhares. São Paulo: Cortez, 1994.

OLIVEIRA, Zilma M. R. Jogo de papéis- um olhar para as brincadeiras infantis. São Paulo: Cortez, 2011.

ROSEMBERG, Fulvia. Mãe que é mãe deixa seu filho em creche? Psicologia, No. 30, São Paulo, 1982, p. 38-42.

ROSEMBERG, Fulvia. 0 a 6: Desencontro de estatísticas e atendimento. Cadernos de Pesquisa, No. 71, São Paulo. 1989a, p. 36-48.

ROSEMBERG, Fulvia O movimento de mulheres e a abertura política no Brasil: o caso da creche. In: ROSEMBERG, Fulvia (Org.) Creche, São Paulo: Cortez, 1989b, p. 90-103. 
ROSSETTI FERREIRA, Maria Clotilde; AMORIM, Kátia S.; SILVA, Ana Paula S.; CARVALHO, Ana Maria A. (Orgs.) Rede de significações e o estudo do desenvolvimento humano. Porto Alegre: Artmed, 2004.

RUBINO, Rejane. Representando o interlocutor no período pré-linguístico. Dissertação (Mestrado em linguística), Pontifícia Universidade Católica, São Paulo, 1989.

SPINK, Mary Jane P. Desvendando as teorias implícitas: uma metodologia de análise das Representações Sociais. In: JOVCHELOVITCH, S. \& GUARESCHI, P. (orgs.) Textos em Representações Sociais. Rio de Janeiro: Vozes, 1994, p. 117-148.

SPODEK, B., Early Childhood Teacher Training: Linking Theory and Pratice. In: KAGAN, S.L. The care and education of America's young children: obsttacles and opportunities, Chicago Press, 1991.

VALSINER, Jaan. Culture and development of children's action: a cultural historical theory of development psychology. New York: John Wileyof Sons, 1987.

VITORIA, Telma. Representações sociais das educadoras sobre as mães e famílias das creches. Dissertação (Mestrado em Saúde Mental), Faculdade de Medicina de Ribeirão Preto da Universidade de São Paulo, Ribeirão Preto, 1997.

VYGOTSKY, Lev S. A formação social da mente. São Paulo: Martins Fontes, 1984.

WEREBE, M.J.G. \& NADEL-BRUlfERT, J. (orgs.) Psicologia - Henri Wallon. São Paulo: Ática, 1986.

ZABALA, A. A prática educativa. Como ensinar. Porto Alegre: Artes Médicas, 1998.

ZABALZA, Miguel Qualidade em educação infantil. Porto Alegre: Artes Médicas

Recebido em: 31/08/2017

Aprovado em: 02/12/2017 